\title{
As Habilidades Sociais de Enfermeiras Gestoras em Equipes de Saúde da Família
}

\author{
Alessandro Simões Marinho ${ }^{1}$ \\ Lilian Maria Borges ${ }^{2}$ \\ ${ }^{1}$ Faculdade Sul Fluminense, Volta Redonda, Rio de Janeiro, Brasil \\ ${ }^{2}$ Universidade Federal Rural do Rio de Janeiro, Seropédica, Rio de Janeiro, Brasil
}

\begin{abstract}
Resumo
A pesquisa, de natureza descritiva, investigou o repertório de habilidades sociais de enfermeiras responsáveis pela gestão de equipes de Saúde da Família. Foi aplicado o Inventário de Habilidades Sociais (IHS-Del Prette) e foram realizadas entrevistas semiestruturadas visando obter a autopercepção das oito participantes acerca de seus recursos e déficits nessas habilidades, sobretudo no que concerne às exigências do trabalho em atenção primária. Os resultados médios do grupo de gestoras foram analisados quanto ao escore total e aos cinco fatores do IHS-Del Prette. A categorização dos relatos obtidos nas entrevistas ocorreu à luz da Análise de Conteúdo de Bardin. Os resultados evidenciaram variadas classes de habilidades sociais, como empatia, assertividade, expressão de sentimentos positivos e resolução de problemas. Em contrapartida, observaram-se dificuldades para comunicação clara e eficaz e para mediar conflitos interpessoais. Destaca-se a relevância de investigações e experiências sistemáticas para o aprimoramento de habilidades interpessoais essenciais à gerência em saúde pública.
\end{abstract}

Palavras-chave: habilidades sociais, saúde da família, enfermeiros, gestão em saúde

\section{The Social Skills of Nurses Managers in Family Health Teams}

\begin{abstract}
The present descriptive research investigated the repertoire of social skills of nurses responsible for the management of Family Health teams. The Social Skills Inventory (IHS-Del Prette) and semi-structured interviews were administered to obtain the self-perception of 8 participants about their resources and deficits in these skills, especially regarding the demands of primary care work. The mean scores of the group were analyzed in relation to the total score and the 5 IHS-Del Prette factors. The categorization of the reports obtained in the interviews took place in light of the Bardin Content Analysis. The results evidenced several classes of social skills, such as empathy, assertiveness, expression of positive feelings, and problem-solving. On the other hand, difficulties for clear and effective communication and mediation of interpersonal conflicts were observed. It is important to highlight the relevance of investigations and systematic experiments for the improvement of interpersonal skills essential to public health management.

Keywords: social skills; family health; nurses; health management
\end{abstract}

\section{Habilidades Sociales de Enfermeras Gerentes en Equipos de Salud Familiar}

\begin{abstract}
Resumen
La investigación, de naturaleza descriptiva, analizó el repertorio de habilidades sociales de enfermeras gerentes responsables en equipos de Salud Familiar. Se aplicó el Inventario de Habilidades Sociales (IHS-Del Prette) y se realizaron entrevistas semiestructuradas con el objetivo de obtener la autopercepción de ocho participantes, sobre sus recursos y déficits en estas habilidades, principalmente, en lo que respecta a las exigencias del trabajo en atención primaria. Los resultados promedio del grupo de gerentes fueron analizados en relación a la puntuación total y a los cinco factores del IHS-Del Prette. La categorización de los reportes obtenidos en las entrevistas se realizó a la luz del Análisis de Contenido de Bardin. Los resultados, evidenciaron varias clases de habilidades sociales, como empatía, asertividad, expresión de sentimientos positivos y resolución de problemas. En contrapartida, se observaron dificultades para una comunicación clara y eficaz y también para mediar en conflictos interpersonales. Se destaca la importancia de investigaciones y experiencias sistemáticas para el perfeccionamiento de habilidades interpersonales esenciales a la gerencia en salud pública.

Palabras clave: habilidades sociales; salud familiar; enfermeras; manejo de la salud
\end{abstract}

\section{Introdução}

Este trabalho tem como ponto de partida e de sustentação as ações desenvolvidas no âmbito dos cuidados primários à saúde no Brasil. Na década de 1990, a atenção primária foi gradualmente se fortalecendo no país como condição necessária para a estruturação dos sistemas locais de saúde e para a efetiva consolidação dos princípios e diretrizes do Sistema Único de Saúde (SUS). A nomenclatura Atenção Básica à Saúde (ABS) foi adotada pelo Ministério da Saúde para se referir à atenção primária, que, em termos generalista e funcional, pode ser definida como um conjunto de ações de saúde no âmbito individual e coletivo que abrange a promoção e proteção da saúde, a prevenção, o diagnóstico e o tratamento de agravos e a reabilitação (Brasil, 
2007). Esse nível da atenção, tendo a Estratégia de Saúde da Família (ESF) como ordenadora do cuidado, deve ser desenvolvido por meio do exercício de práticas de cuidado e gestão participativas, sob forma de trabalho em equipe, dirigidas a populações de territórios definidos (Portaria n ${ }^{\circ} 2.436,2017$ ).

Nesse contexto, a Saúde da Família surge como uma estratégia prioritária de expansão, qualificação e consolidação da ABS por favorecer uma reorientação do processo de trabalho, com potencial para ampliar a resolutividade das ações e o impacto na situação de saúde das pessoas e coletividades, além de propiciar a integralidade do cuidado e uma importante relação custo-efetividade. Seu foco de abordagem é a família, mediante adstrição da clientela, territorialização e atuação multiprofissional e interdisciplinar. Uma equipe de Saúde da Família deve ser formada por, no mínimo, médico generalista ou especialista em Saúde da Família, enfermeiro, auxiliar ou técnico de enfermagem e agentes comunitários de saúde, podendo ser acrescidos a essa composição os profissionais de saúde bucal (Portaria $\left.\mathrm{n}^{\circ} 2.436,2017\right)$.

Esse redirecionamento do modelo de atenção em saúde suscita a necessidade de revisão constante do funcionamento dos serviços e do processo de trabalho das equipes, o que exige dos trabalhadores e gestores maior capacidade de análise, intervenção e autonomia. A consolidação e o aprimoramento da atenção primária como reorientadora do modelo de atenção à saúde requerem, portanto, um processo permanente e contextualizado de qualificação e aperfeiçoamento dos profissionais integrantes das equipes de saúde em meio a desafios técnico-administrativos, gerenciais e estratégicos na ESF (Portaria no 2.436, 2017).

Nesse caminho, em respeito às premissas básicas estabelecidas para qualificar e humanizar o atendimento no SUS, torna-se fundamental realçar as dificuldades técnicas, intrapessoais e, principalmente, interpessoais de gestores na prestação de serviços na atenção primária. Fala-se aqui do profissional responsável por equipes de trabalho, reconhecido na nova Política Nacional de Atenção Básica (PNAB), que necessita apresentar um serviço em saúde de qualidade à população local, além da prestação de contas, no cumprimento de metas, ao Ministério da Saúde (Portaria no 2.436, 2017).

No caso de enfermeiros, entende-se que o aprimoramento da competência interpessoal pode facilitar as relações de trabalho e, assim, proporcionar condições mais viáveis para a resolução de problemas cotidianos. Conforme Mendes (2014, p. 378), “a construção de um repertório socialmente habilidoso é de fundamental importância para enfermeiros na sua relação com equipes de trabalho, tendo em vista que estes possuem a capacidade de influenciar no seu comportamento e, também, na melhora do paciente".

Adentrando ao campo das habilidades sociais, Munari, Costa, Cardoso e Almeida (2003) afirmam a necessidade cada vez maior de se ampliar um modelo de gestão que privilegie o desenvolvimento de habilidades no campo das relações humanas, aspecto tão presente nas condições atuais de trabalho, incluindo a atuação de liderança do enfermeiro. Apesar de inúmeros estudos no campo das habilidades sociais envolvendo, por exemplo, crianças, adolescentes e universitários, há poucas pesquisas no ambiente laboral de gestores de saúde. O processo de desenvolvimento das habilidades sociais nas interações profissionais, tanto quanto nas interações cotidianas, evidencia-se como um objeto de estudo pertinente, no cenário do qual muitas questões podem ser discutidas e avaliadas.

Em meio à diversidade conceitual do tema, as habilidades sociais são descritas por Del Prette e Del Prette (2010) como diferentes classes de respostas do repertório comportamental do indivíduo que este usa para lidar com as demandas requeridas nas interações sociais e que possuem forte probabilidade de produzir consequências reforçadoras para ele próprio e para as demais pessoas do seu grupo social. Contudo, essas habilidades só poderão ser classificadas como habilidades sociais na medida em que venham a contribuir para a competência social (Mendes, 2014; Soares \& Del Prette, 2015). No que tange à competência social, pode-se afirmar que esta possui um sentido avaliativo dos efeitos do desempenho das habilidades sociais, podendo ser considerada como um julgamento no que concerne à adequação do comportamento do indivíduo e do efeito que esse comportamento produz em uma determinada situação (Del Prette \& Del Prette, 2010).

A avaliação de uma conduta como socialmente competente, ou não, deve considerar os valores, regras e representações sociais do contexto cultural e o momento histórico em que acontece esse processo analítico. Reconhecer os condicionantes culturais implica relevar, na caracterização do repertório de habilidades sociais e na avaliação da competência social, os padrões comportamentais historicamente situados, assim como as variantes peculiares de diferentes subculturas (Caballo, 2003).

Como esforço de organização das principais classes de habilidades sociais encontradas na literatura e 
reconhecidas como relevantes ao longo do ciclo vital, a fim de facilitar a identificação de déficits e recursos de habilidades sociais, Del Prette e Del Prette (2017) evidenciaram as seguintes classes: comunicação; civilidade; fazer e manter amizade; empatia; assertiva; expressão de solidariedade; manejo de conflitos e resolução de problemas interpessoais; expressão de afeto e intimidade; coordenação de grupos e falar em público. Miranda e Soares (2014), em pesquisa realizada com médicos e enfermeiros, relatam a importância de habilidades como assertividade, comunicação, empatia, civilidade, expressão de sentimentos positivos e de trabalho para o alcance de uma prática assistencial mais eficaz dos profissionais da saúde.

Contudo, em meio à riqueza de interações que contribuem para a adaptação contextual do indivíduo, encontram-se, também, práticas não favoráveis que, por sua vez, podem desencadear déficits na formação ou no aperfeiçoamento de habilidades sociais, gerando dificuldades que poderão impactar negativamente nas relações interpessoais (Del Prette \& Del Prette, 2013). No entanto, déficits poderão ser reparados mediante treinamento sistemático, em contextos estruturados e por meio de estratégias grupais bem conduzidas.

Abordando especificamente a formação de profissionais de enfermagem, Munari e Bezerra (2004) relatam que, no aperfeiçoamento de enfermeiros para o exercício da gestão, é fundamental a superação da dualidade entre a formação técnica e a necessidade social do profissional. Entretanto, para que isso possa ocorrer, exige-se o desenvolvimento de habilidades específicas, de cunho social/relacional, que permitam aos profissionais tomar decisões individuais e em equipe; liderar com segurança; organizar o trabalho, colocando-o a serviço dos usuários; planejar ações profissionais em saúde; utilizar ferramentas e tecnologias gerenciais e, sobretudo, tornar o processo de gestão uma situação de aprendizado permanente para todos os profissionais que integram as equipes de trabalho.

Considerando a importância do tema em pauta, destaca-se a necessidade de ampliação da produção nacional de estudos sobre habilidades sociais na atuação profissional na área da saúde, sobretudo no que concerne ao exercício da gestão. Nesse sentido, a presente pesquisa surgiu do interesse primordial de conhecer o repertório de habilidades sociais de enfermeiros atuantes na liderança de equipes e analisar a importância dessas habilidades no âmbito das competências gerenciais. $\mathrm{O}$ objetivo, por conseguinte, consistiu em investigar a autoavaliação de enfermeiras que atuavam como gerentes de equipes de Saúde da Família em um município fluminense acerca de seus recursos e déficits de habilidades sociais. É importante frisar que se trata de uma investigação quanti-qualitativa, de cunho descritivo, realizada em congruência com ações que visam criar subsídios para potencializar os processos de formação e desenvolvimento profissional na esfera da atenção primária.

\section{Método}

\section{Participantes}

A pesquisa teve a participação de oito enfermeiras, efetivas ou contratadas, responsáveis pela gestão de equipes de Saúde da Família de um município localizado na região do Médio Paraíba no Estado do Rio de Janeiro, o qual apresentava um contingente de aproximadamente 17.988 habitantes, distribuídos numa extensão territorial de $841,39 \mathrm{~km}^{2}$. O município referido contava com nove Unidades de ESF inseridas no Cadastro Nacional de Estabelecimentos de Saúde (CNES), sendo que uma dessas equipes se encontrava sem um profissional gestor na ocasião da coleta de dados.

A média de idade das profissionais participantes foi de 39 anos, com variação de 29 a 51 anos. Além da graduação em enfermagem, sete delas possuíam pós-graduação na área da saúde, sendo uma dessas especializações em saúde da família. Em termos de exercício profissional, observou-se ampla variação entre elas a respeito do tempo de atuação na atenção primária, indo de seis meses a 20 anos, sendo que sete gestoras iniciaram seus percursos na atenção básica diretamente nessa função. Todas as equipes possuíam um número de profissionais em consonância com as exigências da PNAB.

\section{Instrumentos}

Foram realizadas entrevistas individuais semiestruturadas com base em um roteiro composto por questões destinadas ao levantamento de dados sociodemográficos e profissionais, bem como por onze questões abertas elaboradas com o intuito de estimular as participantes na emissão de respostas sobre os seguintes temas de interesse: importância das habilidades gerenciais no repertório de enfermeiros; habilidades consideradas fundamentais para a prática da liderança de equipes; e autoavaliação de habilidades sociais, considerando aquelas que avaliavam possuir e aquelas que julgavam serem deficientes em seus repertórios no cotidiano profissional. 
Foi aplicado ainda um teste psicológico para aferir o repertório de habilidades sociais das participantes, nesse caso o IHS-Del Prette ${ }^{1}$ (2016), publicado no ano de 2001, que consiste em um instrumento específico de autorrelato, cujo propósito é avaliar o repertório de habilidades sociais do indivíduo. O IHS-Del Prette era composto por cinco fatores: enfrentamento e autoafirmação com risco (F1); autoafirmação na expressão de sentimento positivo (F2); conversação e desenvoltura social (F3); autoexplicação a desconhecidos e situações novas (F4) e autocontrole da agressividade (F5). Esses fatores apresentam habilidades a serem avaliadas em 38 itens com alternativa de respostas em escala do tipo Likert (Del Prette \& Del Prette, 2016).

\section{Procedimentos}

As etapas iniciais da pesquisa consistiram na submissão do seu projeto a uma Comissão de Ética na Pesquisa, que resultou em sua aprovação sob processo de número 980/17, bem como na busca de apoio formal para a coleta de dados junto à Secretária Municipal de Saúde do município em questão. $\mathrm{Na}$ sequência, foi definida com a gerente de Atenção Básica uma data para a apresentação inicial, em grupo, da proposta de pesquisa a todas as enfermeiras responsáveis pelas equipes de Saúde da Família. Os encontros ocorreram de modo individual, em dias e horários mais adequados para cada uma das enfermeiras, em suas unidades de saúde de referência, em locais passíveis de evitar interrupções, manter o sigilo das informações e proporcionar um ambiente climatizado e adequado para aplicação dos instrumentos. Assim, mantendo o planejamento prévio, o pesquisador inicialmente prestou esclarecimentos às gerentes acerca dos objetivos e procedimentos da pesquisa e realizou uma contextualização breve sobre habilidades sociais. O Termo de Consentimento Livre e Esclarecido (TCLE) foi lido, explicado e assinado para, somente depois, ser iniciada a coleta dos dados. Primeiramente, foi aplicado o IHS-Del Prette e, logo em seguida, procedeu-se a realização da entrevista semiestruturada. Os relatos foram gravados em áudio e, posteriormente, foram transcritos na íntegra. Ao final da coleta e análise dos dados, como devolutiva, os principais resultados e conclusões da

O IHS-Del Prette, publicado em 2001, encontra-se com a validade expirada pelo Sistema de Avaliação de Testes Psicológicos (SATEPSI) desde agosto de 2017. No período da coleta de dados, em meados de 2017, o referido instrumento se apresentava em condições de validade pelo Conselho Federal de Psicologia. pesquisa foram disponibilizados às participantes, após devido agendamento.

\section{Análise de Dados}

$\mathrm{Na}$ análise dos dados reunidos nas entrevistas, utilizou-se os conceitos e abordagens da Análise de Conteúdo de Bardin (2016), metodologia de acordo com a qual são necessárias, nesta sequência, a pré-análise e exploração do material e a análise e interpretação dos dados. O pesquisador realizou diversas leituras, análises e interpretações sistemáticas dos discursos dos participantes, procedendo ao consequente agrupamento do conteúdo em categorias temáticas de acordo com as similaridades percebidas em cada eixo de análise. A categorização e interpretação dos relatos das enfermeiras, portanto, ocorreram com base nos núcleos de significado identificados em suas falas e apontados pela literatura especializada na área.

A tabulação dos dados obtidos mediante uso do IHS-Del Prette foi realizada por meio de um sistema de correção informatizada via web e a apuração e interpretação dos seus resultados ocorreu de acordo com as regras de correção e análise do Manual de Aplicação, Apuração e Interpretação do instrumento (Del Prette \& Del Prette, 2016). Nos resultados psicométricos e interpretativos do inventário, foram realizadas análises descritivas dos escores totais e fatoriais. Assim, a classificação do repertório foi dividida em cinco categorias de percentis $(\mathrm{P}): 1)$ repertório deficitário em habilidades sociais $(P<25) ; 2)$ bom repertório de habilidades sociais (abaixo da mediana, $P=25$ e $<$ 50); 3) repertório mediano $(P=50)$; 4 ) bom repertório de habilidades sociais (acima da mediana; $P>50$ e $<$ 75); e 5) repertório bastante elaborado de habilidades sociais $(P \geq 75)$.

\section{Resultados}

A autopercepção das enfermeiras acerca de seus repertórios de habilidades sociais foi organizada em categorias temáticas geradas a partir do conjunto de seus relatos nas entrevistas. Essas categorias estão elencadas a seguir, com suas respectivas descrições, e foram exemplificadas por transcritos textuais elucidativos de seus conteúdos. Na sequência, são apresentadas as análises referentes ao repertório de habilidades sociais das gerentes, avaliadas mediante o uso do IHS-Del Prette. Nos resultados psicométricos e interpretativos desse instrumento, foram realizadas análises estatísticas descritivas dos escores totais, bem como de seus fatores. 
Habilidades Sociais Presentes: Forças Autopercebidas

As enfermeiras avaliaram o próprio desempenho em termos das habilidades sociais que percebiam dispor em seus repertórios no trato diário com as equipes de saúde e usuários. Os dados encontrados foram organizados em sete categorias temáticas: habilidades empáticas, habilidades de resolução de problemas, habilidades de manejo de conflitos, habilidades de motivação do grupo, habilidades de assertividade, habilidades de expressão pessoal e habilidades de partilha de conhecimento.

A categoria "habilidades empáticas" ( $n=5)$ inclui a capacidade autoavaliada das enfermeiras de realizarem escuta qualificada a usuários ou a outros membros da equipe com o propósito de criar um ambiente seguro e acolhedor. Nesse sentido, elas afirmaram ouvir e compreender a outras pessoas de modo empático, assim como fornecer ajuda e mostrar abertura ao diálogo, com estímulo ao relato de experiências e opiniões. Para ilustrar essa categoria, foram destacados os seguintes relatos: "Aí as meninas me perguntaram: o que você fez lá dentro? Falei: ah, eu acolhi, conversei [...], falei que a gente tem que estar se 'pondo' no lugar deles" (ENF A); “[...] tento ouvir, compreender; eu procuro, tento, né, ser amiga. [...] a gente às vezes precisa sentar, conversar, ouvir e entender" (ENF B).

A categoria "habilidades de resolução de problemas" ( $n=3)$ diz respeito à capacidade de buscar, mediante o diálogo, resolver de modo conjunto, situações difíceis que ocorrem ou são relatadas no contexto do trabalho. A verbalização a seguir ilustra essa categoria: "[...] eles trazem para mim os problemas que eles têm na rua, dos pacientes e a gente senta. Eu vejo uma melhor forma de resolver, de ajudar, de pelo menos amenizar" (ENF D).

Os conteúdos que emergiram na categoria "habilidades de manejo de conflitos" ( $n=2)$ remetem às habilidades autorreferidas das enfermeiras quanto à resolução de conflitos interpessoais. Nessa perspectiva, elas disseram atuar como mediadoras em impasses surgidos no cotidiano profissional, o que envolvia o uso de negociação e a administração de conflitos entre membros da equipe. Enquanto exemplo, a fala abaixo ilustra tal afirmação:

"Eu falei: a gente aqui é uma equipe, então a gente precisa das meninas, as meninas precisam de você, você precisa da gente, então é um precisando do outro. Então a gente tem que entrar num acordo para não acontecer isso $[\cdots] ”($ ENF B).
Na categoria "habilidades de motivação do grupo" $(n=3)$, respostas convergiram para mostrar os esforços das enfermeiras em atuarem como motivadoras e reforçadoras para outros membros da equipe. Essa categoria pode ser observada na fala da ENF A: "tento mais motivar eles: pessoal, vamos tentar melhorar isso, vamos fazer isso, aquilo. [...] Eu vejo que eles tão desanimados, eu falo: vamos pessoal, vamos mostrar que a gente pode!”.

A categoria "habilidades de assertividade" $(n=3)$ agrupa os dados obtidos no que concerne à capacidade das entrevistadas de apresentarem uma comunicação clara e assertiva. Isso envolvia comunicar-se de modo a facilitar as interações com os membros da equipe, sentindo-se segura e à vontade para ampliar contatos, iniciar conversação, expor opiniões e dúvidas sem medo de ser criticada, cobrar ações, chamar a atenção por algo, manifestar opiniões e expressar desagrado. Como frase elucidativa dessa categoria, segue o exemplo: "Hoje, qualquer lugar que eu for eu converso com qualquer um, eu puxo assunto. [...] eu sempre fui meia tímida. E hoje não! Hoje se eu tiver dúvida eu pergunto, se eu tiver que chamar a atenção eu chamo, sabe" (sic) (ENF G).

A categoria "habilidades de expressão pessoal" $(n=3)$ pode ser descrita como a iniciativa de expor os próprios sentimentos e emoções na interação com o outro, bem como de reconhecer os próprios erros. Os seguintes relatos ajudam a ilustrar essa categoria: "Tento ser humana. Eu aprendi, no dia a dia, a ser humana, mostrar que a gente tem sentimento [...]. Se eles precisarem que eu chore junto com eles, eu choro" (ENF A); "Se tomei uma decisão, tracei uma meta baseada numa leitura que eu fiz e, de repente: oh, isso não tá funcionando! Eu não tenho problema nenhum em rever e, poxa, realmente isso aqui é desnecessário" (ENF H).

A categoria "habilidades de partilha de conhecimento" ( $n=4)$ diz respeito ao uso pelas enfermeiras de seus conhecimentos e experiências para orientar ou esclarecer outros profissionais, como mostra o seguinte relato ilustrativo: "[...] na mesma hora que eu sentei, comecei a conversar, falei todo tratamento, expliquei toda situação... aí tá, ele relaxou mais um pouco" (ENF A).

Habilidades Sociais Ausentes on Insuficientes: As Limitações em Foco

As narrativas apresentadas pelas entrevistadas evidenciaram suas maiores dificuldades no que tange 
as habilidades necessárias à atuação gerencial. Com base nos relatos obtidos, foram elaboradas quatro categorias, a saber: dificuldades de manejar conflitos e divergências, baixa assertividade, dificuldades para lidar com críticas e falta de clareza na comunicação.

No que diz respeito à categoria "dificuldade de manejar conflitos e divergências" $(n=4)$, as respostas registradas nas entrevistas remetem a dificuldades de metade das enfermeiras em lidar com situações conflitivas na equipe de trabalho, assim como de manejar a diversidade de opiniões. A ENF G expressou: "Eu só acho assim, que é difícil ser gerente, porque, igual eu te falei, a gente tem muito problema com esta questão de relacionamento entre elas [membros da equipe], né?" (sic).

A categoria "baixa assertividade" $(n=3)$ mostra as dificuldades das participantes para emitirem recusas, fazerem valer suas opiniões, darem comandos e/ ou apresentarem-se firmes e seguras em suas ações, o que foi evidenciado, por exemplo, na fala da ENF B: "Eu tinha que falar mais o 'não', entendeu? [...] porque às vezes eu não consigo. [...] Eu já percebi isso: que eu deveria aprender um pouco mais, porque nem tudo tem que se falar 'sim'!" (sic). A ENF F, por sua vez, deixou claro sua baixa assertividade aliada à preocupação em colocar em risco o entrosamento e a amizade com a equipe, conforme demonstrado em seu relato: "Eu queria ser mais firme: vai ser assim e acabou! E, às vezes, eu não consigo por eu ser tão... tão, assim, entrosada com a equipe [...] / [...] Acho que eu precisaria ser um pouco mais firme [...]."

$\mathrm{Na}$ categoria "dificuldade para lidar com críticas" $(n=2)$, observa-se a falta de habilidade das enfermeiras para responderem a críticas recebidas e, aliado a isso, a preocupação delas com o julgamento de outras pessoas acerca de suas ações. O conteúdo dessa categoria foi verificado, por exemplo, na resposta da ENF B: "Eu tenho essa dificuldade. Assim, eu acho que eu vou ficar muito preocupada com o outro, porque, às vezes, eu tenho um pouco disso: ficar preocupada com que o outro acha".

A categoria "falta de clareza na comunicação" (n $=1$ ) demonstra dificuldades de uma das enfermeiras para se expressar com maior clareza e eficiência. Em suas palavras: “É o meu 'palavreado', o jeito de eu falar. Eu acho que tenho que melhorar. Tem hora que eu me perco. Minha comunicação não é boa! Nas reuniões de equipe tem hora que eu falo e vejo que ninguém entendeu" (ENF A).
Inventário de Habilidades Sociais: Escore Total e Resultados dos Fatores

Os dados resultantes da aplicação do IHS-Del Prette e as interpretações decorrentes tiveram como foco a análise do repertório de habilidades sociais das enfermeiras, tendo em vista habilidades presentes e déficits. Foram considerados o escore total e, isoladamente, os cinco fatores avaliados pelo instrumento. A classificação desse repertório de habilidades foi obtida em relação aos resultados normativos do estudo original do IHS-Del Prette (2016), calculado em termos de percentis. Assim, de acordo com as normativas de avaliação do instrumento para amostra feminina, os resultados refletem um repertório satisfatório de habilidades sociais gerais. Para melhor compreensão desse resultado, a Tabela 1 apresenta os escores totais de cada participante e a média da pontuação obtida.

As avaliações do escore fatorial são valoradas tendo em vista a identificação de déficits e recursos em tipos específicos de habilidades, permitindo uma compreensão mais detalhada das habilidades sociais do grupo avaliado. Assim, para apresentação dos itens visando à avaliação dos fatores, foram considerados os resultados apontados como "abaixo da média" e os de maiores pontuações que, por consequência, encontram-se "acima da média". Os valores acima do percentil 50 indicam que o sujeito se encontra entre os $50 \%$ dos indivíduos com escores mais altos em habilidades sociais, e os abaixo de 50 situam-se entre os indivíduos com menores escores tendo por referência a amostragem geral. A Tabela 2 é apresentada para a evidenciação dos resultados dos escores fatoriais das participantes.

De acordo com os dados médios calculados a partir dos percentis de cada gerente para os cinco fatores, tornou-se possível evidenciar e classificar a média dos escores em percentil do grupo. Dos cinco fatores analisados, o F3, referente às habilidades sociais de conversação e desenvoltura social, foi o que apresentou maior criticidade, sendo que metade das enfermeiras exibiram resultados considerados "abaixo da média", o que sugere a maior concentração de déficits nesse conjunto de habilidades. Em relação aos demais, encontrou-se nos fatores F1, F2 e F5 os melhores resultados, classificados como "acima da média", nos quais sete das oito participantes exibiram habilidades satisfatórias. Nesse sentido, para fins descritivos, infere-se que o grupo de gerentes participantes da pesquisa obtiveram resultados satisfatórios no que tange à maioria das habilidades que compõe e caracterizam o "enfrentamento e autoafirmação com 
Tabela 1.

Classificacõoes e Escores Individuais do Grupo de Enfermeiras

\begin{tabular}{|c|c|c|c|}
\hline \multirow{2}{*}{ participantes } & \multicolumn{2}{|c|}{ Escore total } & \multirow{2}{*}{ Interpretação } \\
\hline & $r t$ & $p(\%)$ & \\
\hline enf. a & 103 & 75 & Bom repertório de habilidades sociais \\
\hline enf. b & 109 & 85 & Repertório bastante elaborado de habilidades sociais \\
\hline enf. c & 81 & 23 & Repertório abaixo da média inferior de habilidades sociais \\
\hline enf. d & 92 & 50 & Bom repertório de habilidades sociais \\
\hline enf. e & 120 & 96 & Repertório altamente elaborado de habilidades sociais \\
\hline enf. $\mathrm{f}$ & 112 & 88 & Repertório bastante elaborado de habilidades sociais \\
\hline enf. $g$ & 104 & 78 & Bom repertório de habilidades sociais \\
\hline enf. $h$ & 121 & 96 & Repertório altamente elaborado de habilidades sociais \\
\hline Média & & 73,88 & Bom repertório de habilidades sociais \\
\hline
\end{tabular}

Nota. enf. $=$ enfermeira; $r t=$ resultado total; $p(\%)=$ percentil.

Tabela 2.

Percentis Individuais do Grupo de Enfermeiras por Fator

\begin{tabular}{|c|c|c|c|c|c|c|c|c|c|c|}
\hline \multirow{3}{*}{ participantes } & \multicolumn{10}{|c|}{ Escore fatorial } \\
\hline & \multicolumn{2}{|c|}{ f1 } & \multicolumn{2}{|c|}{$\mathrm{f} 2$} & \multicolumn{2}{|c|}{ f3 } & \multicolumn{2}{|c|}{$\mathrm{f} 4$} & \multicolumn{2}{|c|}{ f5 } \\
\hline & $r t$ & $p(\%)$ & $r t$ & $p(\%)$ & $r t$ & $p(\%)$ & $r t$ & $p(\%)$ & $r t$ & $p(\%)$ \\
\hline enf. a & 9,02 & 58 & 11,34 & 96 & 5,13 & 12,5 & 3,9 & 62,5 & 1,14 & 52,5 \\
\hline enf. b & 8,96 & 58 & 11,7 & 98 & 7,77 & 82,5 & 4,93 & 87,5 & 1,47 & 72,5 \\
\hline enf. c & 7,58 & 38 & 7,61 & 18 & 5,47 & 17,5 & 4,37 & 72,5 & 1,16 & 57,5 \\
\hline enf. $\mathrm{d}$ & 10,35 & 73 & 10,97 & 88 & 5,34 & 17,5 & 2,13 & 22,5 & 0,82 & 42,5 \\
\hline enf. e & 11,89 & 83 & 11,7 & 98 & 10,25 & 100 & 5,52 & 98 & 1,53 & 77,5 \\
\hline enf. $f$ & 10,42 & 73 & 10,74 & 83 & 8,78 & 96 & 4,05 & 67,5 & 0,57 & 37,5 \\
\hline enf. $g$ & 15,1 & 96 & 10,44 & 73 & 4,83 & 12,5 & 2,27 & 22,5 & 1,21 & 62,5 \\
\hline enf. $h$ & 11,47 & 78 & 11,94 & 96 & 9,94 & 100 & 4,93 & 87,5 & 1,21 & 62,5 \\
\hline
\end{tabular}

Nota . enf. $=$ enfermeira; $\mathrm{f}=$ fator; $r t=$ resultado total $p(\%)=$ percentil.

risco", a "autoafirmação na expressão de sentimento positivo" e ao "autocontrole da agressividade". O fator F4 - autoexposição a desconhecidos e situações novas - mostrou resultado um pouco menos expressivo que os supracitados com desempenho "acima da média" revelado por seis das entrevistadas.

\section{Discussão}

A presente pesquisa permitiu conhecer habilidades que constam e que se mostram limitadas no repertório das enfermeiras, conforme percepções delas próprias.
Apresentaram-se com destaque os relatos indicativos da composição de um rol de recursos constituintes da classe de habilidades denominada de empatia, que é definida por Del Prette e Del Prette (2017) como um comportamento social de ouvir e compreender o indivíduo, cujos objetivos situam-se no apoio, na disposição para ajudar e de se colocar no lugar do outro, principalmente quando este se encontra em situações difíceis. Nesse sentido, a empatia representa um padrão de comportamento desejável na atuação cotidiana dos profissionais de saúde. Falcone (1999) ressalta a valoração da empatia nas relações de trabalho, de modo 
a contribuir para a redução de conflitos e possibilitar maior qualidade nos relacionamentos interpessoais. Essa habilidade foi destacada por Terezam, Reis-Queiroz e Hoga (2016) em pesquisa sobre a importância da empatia no cuidado em enfermagem, ao afirmarem ser esta uma das habilidades mais relevantes para a base da comunicação efetiva. Todavia, é importante melhor conhecer como a compreensão empática é percebida e claramente exercida por gestores enquanto facilitadora de suas relações intersubjetivas no trabalho, já que costuma haver confusões no entendimento do termo, por vezes tratado como simpatia, e sua prática apresenta muitas nuances vivenciais, que pressupõe, em uma perspectiva fenomenológica, "um movimento de compreensão da experiência do outro, um testemunho sensivel daquilo que ele vive" (Ranieri \& Barreira, 2012, p. 12), o que pode requerer certa preparação ou tomada de consciência, mas é essencialmente um ato natural.

Em relação à assertividade, pôde-se observar indícios de habilidades constitutivas dessa classe no repertório de metade das enfermeiras. A assertividade refere-se a comportamentos sociais esperados em situações em que haja desrespeito ou ameaça de perda dos direitos, bem como necessidade de enfrentamento em situações de desequilíbrio na vivência interpessoal (Del Prette \& Del Prette, 2017). Além das verbalizações desse tipo de habilidade, pôde-se, ao mesmo tempo, presumir comportamentos assertivos das participantes mediante os resultados do IHS-Del Prette, considerando a classificação média de "bom repertório de habilidades sociais" nos dois fatores com um maior número de habilidades constituintes da classe de assertividade: o enfrentamento e autoafirmação com risco (F1) e o autocontrole da agressividade (F5).

No entanto, houve também evidências de baixa assertividade no repertório de três entrevistadas, cujas falas mostraram suas dificuldades em apresentar um padrão assertivo no cotidiano de trabalho, o que reforça a importância de se considerar a variabilidade do desempenho social de acordo com as contingências circundantes à situação social (Del Prette e Del Prette, 2017). Grilo (2012) destaca deficiências na aplicabilidade de uma comunicação assertiva por profissionais de saúde, incluindo os enfermeiros. Nesse cenário, ratifica a essencialidade da assertividade no repertório de habilidades desses profissionais, afirmando ser esta uma das habilidades mais relevantes no gerenciamento de pessoas.

Em especial, observou-se a dificuldade em emitir recusas, o que pode ser negativo no âmbito do exercício da gerência, quando limites devem ser fixados, ainda que com alguma flexibilidade, em termos, por exemplo, da atenção a normas e protocolos, com vista ao alcance de um bom funcionamento dos serviços. Supõe-se que, na tentativa de se mostrarem mais próximas e atentas às necessidades dos profissionais da equipe, algumas gestoras tinham dificuldades para proferirem o "não", interpretando a negativa como um comportamento ofensivo, tendendo, portanto, para o outro extremo, da passividade, o que dá margem à frustração e à insegurança.

É importante pontuar os benefícios de um padrão assertivo de resposta no trabalho, enquanto um modo de agir coerente com as convicções do sujeito, sem ofender a outros, que se destaca pela segurança em suas atitudes e decisões em prol de uma forma colaborativa e respeitosa de atuação. A baixa assertividade pode, inclusive, comprometer o desenvolvimento da equipe, na medida em que a dificuldades do gestor em dar um feedback apropriado com receio de ser julgado pode levar os trabalhadores a compreenderem as próprias respostas inadequadas ou abusivas como corretas ou toleráveis, sem atentar para o que precisa ser melhorado. Por outro lado, um gestor assertivo pode fornecer modelos desse tipo de comportamento aos demais membros da equipe, favorecendo uma comunicação mais efetiva e exitosa. Conforme enfatiza Mendes (2014), o mundo do trabalho contemporâneo valoriza profissionais, não somente capacitados tecnicamente, mas também socialmente competentes, sendo capazes de atuar de forma assertiva, resolutiva e motivadora.

$\mathrm{Na}$ apuração do IHS-Del Prette, as habilidades componentes da expressão de sentimentos positivos (F2) apresentaram uma classificação de repertório "bastante elaborado de habilidades sociais" no escore dos cinco fatores. Essa classe é caracterizada por Del Prette e Del Prette (2017) como habilidades do indivíduo para lidar com demandas de expressão de afeto positivo e de afirmação de autoestima. Assim, pôde-se concluir que, a maioria das participantes exibiram resultados interpretados como "acima da média" nesse fator. Já as respostas concernentes à classe de resolução de problemas foram destacadas pelas gestoras ao expressarem como agiam junto às equipes para minimizar dificuldades observadas nos processos de trabalho, principalmente junto aos usuários.

A habilidade de manejo de conflitos, apesar de ter estado presente no repertório de duas enfermeiras foi mais citada enquanto uma deficiência a ser superada. De fato, no relato das gestoras, o manejo de 
conflitos e divergências se mostrou a habilidade com maior déficit percebido. Esse resultado apresentou conformidade com os achados de pesquisa realizada por Nunes, Carvalho, Nicolleto e Cordoni Junior (2016), na qual estes apontam, a partir de um estudo realizado com gestores da atenção primária, evidências de fragilidades desses profissionais na mediação de relações conflituosas do dia a dia. Dificuldades de mediação por parte de enfermeiros gestores se estendem a outros estudos, como é o caso do apresentado por Silva, Diniz e Rosa (2012), que argumentam sobre a importância de se desenvolver habilidades de manuseio de conflitos na função gerencial para que seja possível realizar uma administração funcional com êxito na atenção primária. Assim, considerando tal relevância, fica sugestionada a indicação de habilidades de manejo de conflitos em Treinamentos de Habilidades Sociais (THS) nesse contexto.

Levando em consideração ainda a relevância da habilidade de comunicação para a função gerencial e o caráter não somente corretor, mas igualmente preventivo e potencializador do THS, sugere-se, também, capacitações que visem aquisição e/ou o aperfeiçoamento das habilidades de conversação e desenvoltura social. $\mathrm{Na}$ análise do escore fatorial do IHS-Del Prette, o F3, constituído por habilidades dessa classe, foi o fator no qual metade das enfermeiras apresentou habilidades "abaixo da média". Carmelo, Rocha, Chaves, Silva e Soares (2016) apontam a comunicação como essencial no rol de habilidades de um gestor em saúde, de maneira que possa sensibilizar a equipe e fomentar sua motivação. Em estudo realizado em Portugal a respeito da influência da liderança na qualidade das ações de enfermeiros, Fradique e Mendes (2013) encontraram a comunicação como predominante no rol de habilidades dos gestores.

Das oito gestoras, apenas uma evidenciou a necessidade de participação em programa de THS. No entanto, no que diz respeito às indicações para um programa dessa natureza, vale a consideração de que a correção de déficits não constitui o único objetivo, pois se vislumbra também intervenções preventivas e o aperfeiçoamento de habilidades já existentes no repertório do indivíduo. Assim, os benefícios de um THS são estimados independentemente dos profissionais apresentarem ou não um déficit significativo de habilidades desta natureza, na medida em que pode favorecer, de um modo geral, uma melhor preparação de gerentes para o enfrentamento de desafios típicos do trabalho em saúde.

\section{Considerações Finais}

Os resultados evidenciaram o autoconhecimento das enfermeiras quanto ao repertório de suas habilidades sociais. Ficou clara a existência tanto de recursos como de deficiências de habilidades importantes no campo gerencial quando consideradas as novas abordagens de gestão em saúde, que se opõem a modelos tecnicistas, pautados no paradigma biomédico, e colocam em evidência o trabalho em equipe na produção do cuidado em saúde.

Empatia, assertividade e resolução de problemas tiveram suas relevâncias ratificadas nos autorrelatos, conforme verificado na literatura e nos documentos governamentais que fundamentam o comportamento de um gestor em saúde. Já no que se refere aos principais déficits, as gestoras relataram limitações principalmente quanto a assertividade, sobretudo o dizer "não", e ao manejo de conflitos e divergências. Outra classe evidenciada com indicadores significativos para THS foi a de comunicação e desenvoltura social (F3), observada com mais clareza nos resultados do IHS-Del Prette.

Em síntese, os resultados dos instrumentos de autorrelato demonstraram um repertório de habilidades sociais das enfermeiras compatível com a função gerencial. No entanto, deficiências importantes e que podem intervir negativamente no exercício da gerência em Saúde da Família também foram apuradas. Nesse sentido, os dados apontaram direcionamentos para o planejamento de programas de THS, com vistas à qualificação de enfermeiros gestores para uma vivência resolutiva diante de desafios que peculiarizam a atenção primária. Compreende-se que a integração de habilidades técnicas e sociais tem considerável importância na construção da figura de um enfermeiro líder responsável pelo crescimento funcional e humano de sua equipe.

Por fim, vale a atenção às limitações da pesquisa no que tange ao número de participantes e ao fato destas terem sido recrutadas em um mesmo município, o que dificulta generalizações. Ademais, pelo fato de o estudo ter centrado a análise de dados com base unicamente no autorrelato, cabe questionar o modo como essas habilidades eram desempenhadas na prática laboral. Nesse sentido, sugere-se mais estudos de investigação das habilidades sociais e gerenciais de enfermeiros gestores na ABS para que se agregue mais valor a essa área, proporcionando resultados científicos capazes de contribuir para a criação cada vez mais ampla e eficaz de estratégias que possam intervir qualitativamente em um campo de atuação tão complexo e incipiente no Brasil.

Psico-USF, Bragança Paulista, v. 25, n. 3, p. 573-583, jul./set. 2020 


\section{Referências}

Bardin, L. (2016). Análise de Conteúdo. São Paulo: Edições 70 .

Brasil (2007). Conselho Nacional de Secretários de Saúde. Atenção Primária e Promoção da Saúde. Conselho Nacional de Secretários de Saúde. Brasília: CONASS.

Caballo, V. E. (2003). Manual de avaliação e treinamento das habilidades sociais. São Paulo: Santos Livraria e Editora.

Carmelo, S. H. H., Rocha, F. L. R., Chaves, L. D. P, Silva, V. L. S., \& Soares, M. I. (2016). Competências profissionais e estratégias organizacionais de gerentes de enfermagem. Ciencia y Enfermeria, XXII(1), 7586. doi: 10.4067/S0717-95532016000100007

Del Prette, A., \& Del Prette, Z. A. P. (2013). Programas eficaces de entrenamiento en habilidades sociales basados en métodos vivenciales. Apuntes de Psicología, 31(3), 67-76. Recuperado de http:// www.apuntesdepsicologia.es/index.php/revista/ article/view/300/280

Del Prette, A., \& Del Prette, Z. A. P. (2016). Inventário de habilidades sociais: Manual de aplicação, apuração e interpretação. 6 ed. São Paulo: Casa do Psicólogo.

Del Prette, A., \& Del Prette, Z. A. P. (2017). Competência Social e Habilidades Sociais: manual teórico-prático. Petrópolis: Editora Vozes.

Del Prette, Z. A. P., \& Del Prette, A. (2010). Habilidades sociais e análise do comportamento: Proximidade histórica e atualidades. Revista Perspectivas, 01(02), 104-115. Recuperado de http:// pepsic.bvsalud.org/scielo.php? pid $=$ S2177-35482010000200004 \&script=sci_ abstract\&tlng $=\mathrm{pt}$

Falcone, E. (1999). A avaliação de um programa de treinamento da empatia com universitários. Revista Brasileira de Terapia Comportamental e Cognitiva, 1(1), pp. 23-32. Recuperado de http://pepsic. bvsalud.org/scielo.php?script=sci_arttext\&pid $=$ S1517-55451999000100003

Fradique, M. de J., \& Mendes, L. (2013). Efeitos da liderança na melhoria da qualidade dos cuidados de enfermagem. Revista de Enfermagem Referência, III série, 10, 45-53. doi: 10.12707/RIII12133.
Grilo, A. M. (2012). Relevância da assertividade na comunicação profissional de saúde-paciente. Psicologia, Saúde \& Doenças, 13(2), 183-197. Recuperado de http://www.scielo.mec.pt/scielo.php?script $=$ sci_arttext\&pid $=$ S164500862012000200011

Mendes, D. L. (2014). Treino em habilidades sociais e intervenção cognitivo- comportamental em grupo de enfermagem. Em T. Rudnicki \& M. M. Sanchez. Psicologia da saúde: A prática de terapia cognitivo-comportamental em hospital geral. Novo Hamburgo: Sinopsys, 365-380.

Miranda, J. M., \& Soares, A. B. (2014). Habilidades sociais e autoeficácia de médicos e enfermeiros: Um estudo comparativo. Revista de Ciências Humanas, 48(1), 138-153. doi: 10.5007/2178-4582.2014v48n1p138

Murani, D. B., \& Bezerra, A. L. Q. (2004). Inclusão da competência interpessoal na formação do enfermeiro como gestor. Revista Brasileira de Enfermagem, 57(4), 484-486. Recuperado de http://www.scielo. $\mathrm{br} / \mathrm{pdf} /$ reben/v57n4/v57n4a20.pdf

Murani, D. B., Costa, H. K. da, Cardoso, A. H. A., \& Almeida, C. C. O. de F. (2003). Características da competência interpessoal do enfermeiro: estudo com graduandos de enfermagem. Revista Brasileira de Enfermagem, 56(5), 484-487. doi: 10.1590/ S0034-71672003000500003

Nunes, E. de F. P. de A., Carvalho, B. G., Nicolleto, S. C. S., \& Cordoni Junior, L. (2016). Trabalho gerencial em Unidades Básicas de Saúde de municípios de pequeno porte no Paraná, Brasil. Interface, 20(58), 573-584. doi: 10.1590/1413-812320141911.18582013

Portaria ñ 2.436, de 21 de setembro de 2017. Aprova a Política Nacional de Atenção Básica, estabelecendo a revisão de diretrizes para a organização da Atenção Básica, no âmbito do Sistema Único de Saúde (SUS). Diário Oficial da União, Brasilia. Recuperado de http://bvsms.saude.gov.br/bvs/saudelegis/ gm/2017/prt2436_22_09_2017.html

Ranieri, L. P., \& Barreira, C. R. A. (2012). A empatia como vivência. Memorandum, 23, 12-31. Recuperado de http://www.fafich.ufmg.br/memorandum/ wpcontent/uploads/2012/10/ranieribarreira01. pdf

Silva, G. S., Diniz, B. G., \& Rosa, V. das G. (2012). Administração de conflitos: Análise de percepções de 
enfermeiros Gerentes. R. Eferm. Cent. O. Min., 2(3), 358-368. doi: 10.19175/recom.v0i0.227

Soares, A. B, \& Del Prette, Z. A. P. (2015). Habilidades sociais e adaptação à universidade: Convergências e divergências dos construtos. Análise Psicológica, 2, 139-151. doi: 10.14417/ap.911
Terezam, R., Reis-Queiroz, J., \& Hoga, L. A. K. (2017). A importância da empatia do cuidado em saúde e enfermagem. Revista Brasileira de Enfermagem [Internet], 70(3), 669-670. doi: 10.1590/0034-7167-2016-0032

Recebido em: 06/10/2018

Reformulado em: 30/08/2019

Aprovado em: 11/10/2019

Sobre os autores:

Alessandro Simões Marinho é psicólogo formado pelo Centro Universitário Salesiano de São Paulo, com o mestrado concluído, no ano de 2018, pela Universidade Federal Rural do Rio de Janeiro e integrante do corpo docente da Faculdade Sul Fluminense, desde 2017. Realiza pesquisas e orienta trabalhos em nível de graduação e atua, também, como Diretor de Departamento de Atenção Primária em Saúde na Prefeitura Municipal de Rio Claro-RJ. E-mail: aless.simoes@gmail.com

ORCID: https://orcid.org/0000-0002-4672-9636

Lilian Maria Borges é psicóloga formada pela Universidade Federal do Pará e concluiu o doutorado em psicologia, no ano de 2011, pela Universidade de Brasília. Integra o corpo docente do Departamento de Psicologia e do Programa de Pós-graduação em Psicologia da Universidade Federal Rural do Rio de Janeiro desde 2014 e realiza pesquisas e orienta trabalhos em nível de graduação, mestrado e doutorado na área da Psicologia da Saúde/Hospitalar.

E-mail:1borgesufrrj@gmail.com

ORCID: https://orcid.org/0000-0002-6570-0417

Contato com os autores:

Instituto de Educação, Departamento de Psicologia, Sala 19, Rodovia BR 465, Km 07, s/n, Zona Rural Seropédica-RJ, Brasil

CEP: 23890-000 